\title{
Polyelectrolyte-nanocomposite for enhanced oil recovery: influence of nanoparticle on rheology, oil recovery and formation damage
}

\author{
Akinleye O. Sowunmi ${ }^{1} \cdot$ Vincent E. Efeovbokhan $^{1} \cdot$ Oyinkepreye D. Orodu ${ }^{2} \cdot$ Babalola A. Oni ${ }^{1,3}$
}

Received: 13 September 2021 / Accepted: 26 October 2021 / Published online: 6 November 2021

(c) The Author(s) 2021

\begin{abstract}
Gum arabic (GA) capacity as an enhanced oil recovery (EOR) agent is studied and compared to the commonly applied xanthan gum (XG). FTIR and TGA characterisation of these two polyelectrolytes and a rheology study by viscosity measurement was conducted on their polymeric and nano-polymeric solution at varying concentrations of the polymers and nanoparticles (NP). Coreflooding experiments were conducted based on a sequence of waterflooding and three slugs of increasing concentration of polymeric (and nano-polymeric) solutions to evaluate EOR performance. Results show similar rheology and oil recovery for $1.0 \mathrm{wt} \% \mathrm{GA}$ and a $0.1 \mathrm{wt} \% \mathrm{XG}$ polymeric solution. And the viscosity of GA tends to be Newtonian at a relatively high shear rate. The magnitude of incremental oil recovery of the first slug is independent of the GA concentration but significant for XG. However, the impact of nano-polymeric solution on oil recovery is higher than the polymeric solution. The increase in NP concentration played a vital role in oil recovery, thereby connoting the significance of IFT, contact angle, and its associated mechanisms for EOR. And FTIR affirms that the hydroxyl group in XG is less than GA, thus responsible for adsorption of GA compared to XG.
\end{abstract}

Keywords Gum arabic $\cdot$ Xanthan gum $\cdot$ Polyelectrolyte $\cdot$ Viscosity $\cdot$ Enhanced oil recovery $\cdot$ Nanocomposite

\section{Introduction}

Generally, about one-third of the crude oil found in known reservoirs is economically recoverable based on the primary recovery methods through gas expansion and other natural forces in the reservoir and waterflooding through secondary recovery (Austad et al. 2010). Hence, the much needed tertiary recovery popularly referred to as enhanced oil recovery (EOR). EOR is a process that involves the injection of substances (which is not initially present in the reservoir) into a petroleum reservoir to achieve additional recovery beyond what is obtainable from the primary and secondary methods of oil recovery (Nowrouzi et al. 2019; Saha et al. 2018). A standard EOR method is chemical flooding.

Oyinkepreye D. Orodu

oyinkepreye.orodu@ covenantuniversity.edu.ng

1 Department of Chemical Engineering, Covenant University, P.M.B 1023, Ota, Ogun State, Nigeria

2 Department of Petroleum Engineering, Covenant University, P.M.B 1023, Ota, Ogun State, Nigeria

3 Department of Chemical Engineering, China University of Petroleum, Beijing, China
Various forms of chemical EOR have been employed (e.g. alkaline, surfactant, polymer and their combinations) at the reservoir conditions of high salinity and high temperature. However, there is still some constraint in the total usage, such as high-cost chemicals that are not environmentally friendly, production shortage and complicated instruments (Li et al. 2017; Zhang et al. 2014; Corredor et al. 2019a). Hence, the need for further investigation and development of novel chemicals.

The adoption of polymers, a chemical EOR technique and its improvement by blending with nanoparticle are of particular focus in this study. Polymers aids mobility control based on their high viscosity, and with regard to electrostatic potential, they may be classified as non-ionic, anionic and cationic. A non-ionic polymer has no electrical charges. Polyelectrolytes combine the properties of polymer and electrolyte. Hence, they can considerably alter the properties of suspensions and aqueous solutions and interact with macromolecules of opposite charges, small ions, and neutral particles (Budd 1989). Examples of polyelectrolytes are gum arabic and the popularly used xanthan gum for EOR studies. Gum arabic, a polyelectrolyte, is an emulsifier with binding, stabilising and shelf-life enhancing properties. 
It is a complex and branched heteropolysaccharide which comprises of 1, 3 -linked $\beta$-D-galactopyranosyl units. Compounds of D-glucuronic acid, L-arabinose and L-rhamnose have been found as constituents of this polyelectrolyte (Xu et al. 2017).

Polymers are mixed with nanoparticles to form nanocomposites (nano-polymeric solution), and different nanoparticles have been reported to have varying effects on polymers' viscosity. Khan et al. (2018) studied the impact of silicon oxide, titanium oxide and ferric oxide on anionic polyacrylamide's viscosity. The three nanoparticles increased the viscosity of polyacrylamide. This finding was attributed to the electrostatic interactions between the polymer and the nanoparticles. Thus, increasing the concentration of nanosilica also increases the oil recovery achieved using polyacrylamide.

Other works on nanocomposite are the grafting of nanoparticles' surface with polymer. This is a recently advanced approach, proving to improve the stability in an aqueous solution (Hamidi et al. 2020). Behzadi and Mohammadi (2016) demonstrated silicon oxide with $\mathrm{H}-\left(\mathrm{O}-\mathrm{CH}_{2}-\mathrm{CH}_{2}\right)_{\mathrm{n}}-\mathrm{OH}$ and propyl chains positively impact enhanced oil recovery using glass micromodels. There was an improved oil recovery due to the change in wettability from oil to water wet based on nanoparticle (NP). Rezvani et al. (2018) confirmed from the experimental study, IFT, oil viscosity and contact angle declined when using a polymercoated $\mathrm{Fe}_{3} \mathrm{O}_{4}$ with seawater. Hence, it improved oil recovery. El-Hoshoudy et al. (2016) studied polyacrylamide polymergrafted $\mathrm{SiO}_{2}$ nanoparticles, confirmed thermal and shear resistance behaviour and high anti-salinity with thickening behaviour. Thus, it can withstand reservoir temperature and pressure. Therefore, nanocomposites are essential due to their exceptional properties, which combines the benefits of inorganic nanoparticles and organic polymers (Mishra et al. 2014; Kortam et al. 2017).

The primary focus of this study is the impact of gum arabic and its blend with nanoparticle on oil recovery performance. Previous studies by Orodu et al. (2019) had negated prior findings of the polymeric solution's rheological behaviour. The polymeric solution exhibited relatively non-Newtonian behaviour at all investigated shear rate as against the findings of Li et al. (2009), Sanchez et al. (2002) and other authors. Newtonian and non-Newtonian behaviour depends on the shear rate, with Newtonian at low shear rate. Gum arabic (GA) is a low viscosifying enhancement agent and has a low molecular weight, unlike other biopolymers, and has oil-brine IFT reduction capacity (Chen et al. 2013; Zou et al. 2008). GA's weak surfactant property can be enhanced as alluded by Patel and Goyal (2015), Negin et al. (2016) and Rashid (2019) with materials for improved microscopic interactions such as NP as against the limiting macroscopic impact of the polymer's viscosifying property for EOR. Its capacity to reduce oil-brine IFT is related to this polymer's ability to migrate to the oil-water interface, in which the hydrophobic polypeptide chain interacts with oil and the hydrophilic arabinogalactan unit interacts with water (Akbari et al. 2017). It should be noted that its surface activity properties are weak compared to most other surfactants (Chen 2015), in particular, polyelectrolytes such as xanthan gum, which has been widely researched and documented for EOR. An attestation to further IFT reduction of nano-polymeric solution of GA with silica nanoparticle is the study by Rashid (2019). IFT reduced considerably with an increase in temperature from $30{ }^{\circ} \mathrm{C}$ to reservoir temperatures.

Furthermore, GA nanocomposite is yet to be compared with conventional and green EOR agents to build a solid and compelling case for its use by the industry. With the additional shortcoming of GA, mainly due to its short stability issues, caused by self-aggregation in water solution and brine, and at oil/water interface, its use may be problematic (Xiang et al. 2015; Li et al. 2009; Ido et al. 2008). GA's capability to dissociate and reassociate makes neither high shear mixing nor filtration a solution (Isobe et al. 2020; Li et al. 2011). The increase in hydrodynamic size is by the molecules' associative nature. The only other experimental study on GA nano-polymeric solution by Hamidi et al. (2020) for EOR was extensive in characterisation. However, it lacked a comprehensive investigation of rheology at varying NP concentration. Also, micromodel was utilised for EOR evaluation instead of natural core plugs, which are preferred due to its mineral content and the nature of the pore throat interconnectivity and three-dimensional tortuosity of linked pores.

This study has extensively investigated the rheology of GA and its NP-polymeric solution compared to the commonly applied XG biopolymer and XG NP-polymeric solution at a broad range of individual constituents' concentration. The impact of GA on oil recovery performance during coreflooding was compared with the relatively few past works in literature to bolster the application of the polymer, which is abundant in nature. Also, the impact of NP in NPpolymeric solution based on the constituent concentration as it affects oil recovery was studied. A secondary aim was to characterise polymers and porous media before and after flooding to elicit flooding performance.

For the first time, a broad range weight fraction of gum arabic with nanoparticles of silica and alumina was investigated and compared with xanthan gum, unlike previous studies with no basis for comparison. XG, a commonly applied polymer in laboratory EOR studies, was the ideal choice and never before compared with GA in terms of oil recovery performance. This enabled the selection of a similar bulk viscosity profile of both the biopolymers of GA and XG for investigating EOR and the impact of nanoparticles. Furthermore, the in situ viscosity of GA was put in the spotlight 
for the first time to juxtapose its performance with $\mathrm{XG}$ in comprehending and eliciting oil recovery mechanism; and the qualitative assessment of GA nanocomposite on permeability impairment by SEM images before and after core flooding. Studying GA is borne out of the necessity of this polymer's relative abundance, low cost and green nature as a substitute for well-established polymers.

\section{Materials and method}

\section{Materials}

Native state gum arabic polymer (GA) was purchased from Panteka market in Kaduna state, Northern Nigeria (10.3764 $\mathrm{N}, 7.7095^{\circ} \mathrm{E}$ ), and commercial xanthan gum (XG) from Ojota Chemical Market in Lagos, Nigeria. Silicon oxide nanoparticles (98\% purity with an average particle size of $30-50 \mathrm{~nm}$ ) and aluminium oxide nanoparticles (98\% purity with an average particle size of 30-60 nm) were purchased from Sigma-Aldrich, USA. Core plugs and medium crude oil (24.8 ${ }^{\circ}$ API and $14.5 \mathrm{cP}$ apparent viscosity) were from Nigeria's Niger Delta region. Deionised water was used for preparing the polymers fluids and the polymer nanocomposites. Toluene of HPLC grade was used in the cleaning of the core plugs.

\section{Preparation of polyelectrolyte fluid and nanocomposite}

Polymer fluid was prepared following API 63 standard practice by adding the GA directly to deionised water according to the following weight percentages: $0.4,0.5,1.0,5$ and $15 \% \mathrm{w} / \mathrm{w}$. The same applies to the XG of $0.1,0.5$ and $1.0 \%$ w/w. Polymer nanocomposites were prepared by first adding nanoparticle to deionised water and then adding the GA and $\mathrm{XG}$, respectively.

\section{Bulk (viscometric) viscosity measurement}

The viscosity of the polyelectrolyte was measured using an OFITE 800 Viscometer to determine its flow properties against shear. The viscometer is equipped with a heating mantle for high-temperature measurements and eight regulated test speeds corresponding to different shear rates. A simple bob and rotor setup characterises the viscometer, and results are taken from dial readings that are easily converted to viscosity values. All viscosity measurements for the polymers were carried out using the R1B1 rotor bob within a shear rate range of $10.21-1021.38 \mathrm{~s}^{-1}$ and a temperature range of $30-90{ }^{\circ} \mathrm{C}$. Before the measurements, the viscometer was calibrated using the fluid based calibration test kit. For the experiments, the viscosity sleeves were fitted, and then the polymer fluid was poured into the cup up to the fill line of the viscosity sleeves for measurement. The same was done for the GA and XG nanocomposite. Although viscosity measurement for the polymers was done using weight percentages ranging from 0.4 to 15 , only the lower weight percentages were used in core flooding experiments to avoid blockages of the flow lines.

\section{In situ (porous media) viscosity estimation}

The computation of in situ viscosity is commonly linked to bulk viscosity (Zamani et al. 2017; Cannella et al. 1988; Eberhard et al. 2019; Hirasaki and Pope 1974) and recently by direct numerical simulation. The former approach is semi-analytical, neglecting viscoelasticity and time dependence of polymers. This effectively fits the widely accepted shear-thinning fluid model of Cannella et al. (1988) for xanthan gum given as;

$\gamma_{\text {app }}=6\left(\frac{3 n+1}{4 n}\right)^{\frac{n}{(n-1)}} \frac{u}{\sqrt{k_{w} \phi S_{w}}}$

$\mu_{\text {app }}=\mu_{\infty}+K\left(\frac{3 n+1}{4 n}\right)^{n}\left(\frac{u}{\sqrt{k_{w} \phi S_{w}}}\right)^{(n-1)}$

where $u$ is Darcy velocity $(\mathrm{cm} / \mathrm{s}), k_{w}$ permeability $\left(\mathrm{cm}^{2}\right), \gamma_{\text {app }}$ apparent shear rate $\left(\mathrm{s}^{-1}\right), \phi$ porosity, and $S_{w}$ water saturation, $\mu_{\text {app }}$ apparent viscosity, and $\mu_{\infty}$, brine viscosity ( $1 \mathrm{cp}$ ); $K$ and $n$ are from the bulk rheology model and represents consistency index and power-law exponent, respectively.

Xanthan gum remains a shear-thinning and non-Newtonian fluid at a high shear rate as against the shear-thickening of the behaviour of hydrolysed polyacrylamide in the porous media (Cannella et al. 1988; Scott et al. 2020). For gum arabic, $\mathrm{Li}$ et al. (2011) asserts the dominance of viscous contribution to bulk viscosity for a shear rate above $10 \mathrm{~s}^{-1}$ due to the breakdown of molecular association and tends to Newtonian behaviour at a higher shear rate (Mariod 2018). Thus, it fits the Carreau expression presented in Eq. (3) for viscosity used to develop Eq. (2). Hence, Eqs. (1) and (2) are applied to gum arabic in situ shear rate and viscosity as an approximation.

$\mu=\mu_{\infty}+\left(\mu_{o}-\mu_{\infty}\right)\left(1+\left(\frac{K}{\mu_{o}}\right)^{\frac{2}{n-1}} \gamma^{2}\right)^{\frac{n-1}{2}}$

Equation (3) reduces to Eq. (4) at moderate to high shear rates and thus applied in this study to obtain ' $K$ ' and ' $n$ ' for the link between in situ and bulk viscosity.

$\mu=K \gamma^{n-1}$

where $\mu_{o}$ is Newtonian viscosity at zero shear rate and all other variables are presented in Eqs. (1) and (2). 


\section{Core flooding tests}

Niger Delta core plugs (see Table 1) were first cleaned in a Soxhlet extractor using toluene and then dried. Subsequently, porosity and pore volume were determined with the aid of a manual core saturator (Vinci TS-010-00001-0) at a pressured cell of 2000 psi. Core flooding was conducted at ambient conditions and confining pressure of $200 \mathrm{psi}$. The schematic of the flooding setup is as shown in Fig. 1. Liquid permeability was established by OFITE reservoir permeability tester (RPT). The flooding was commenced by core saturation with brine using the saturator and sequentially with the RPT for the imbibition scheme. The drainage process by oil to displace brine gave rise to the initial water saturation before secondary recovery by waterflooding and EOR by polymer-polymeric nanocomposite solution. EOR was initiated after waterflooding, and effluent sampling was not automated, hence collecting displaced fluids every four (4) minutes. This aided measurement and computation of produced oil, brine, water saturation and oil recovery.

Imbibition and drainage processes were at an injection rate of $3 \mathrm{~cm}^{3} / \mathrm{min}$. In doing so, irreducible water saturation and the core plug restored to a state in likeness to a reservoir's natural and undisturbed condition. Oil recovery was commenced by waterflooding at an injection rate of $0.5 \mathrm{~cm}^{3}$ / min until only water production. This was followed by polymer (or polymeric nanocomposite) no more production of oil. Polymer and nanocomposite flooding was a three-stage sequential flooding of increased concentration. At first, $0.4 \%$ concentration of polymer solution, $0.5 \%$ and finally $0.1 \%$ is for only polymer flooding, whereas for polymeric nanocomposite flooding, it's a mixture of $1 \% \mathrm{GA}+0.1 \%$ nanoparticle (NP), followed by $1 \% \mathrm{GA}+0.3 \% \mathrm{NP}$, and finally $1 \% \mathrm{GA}+0.5 \% \mathrm{NP}$, respectively. Flooding at each stage of a particular polymer or polymeric nanoparticle solution is until no produced oil or only water, and polymer solution is produced.

Scanning electron microscopy (SEM) images were taken for the core plugs before and after the core flooding experiments. This was done to examine the extent of permeability impairment caused by the injection of the nanocomposite. Images were taken using a Quanta SEM 450 Thermo-Fisher Scientific equipment. Core plugs were coated with gold to make them conductive. The samples were scanned using a $3-5 \mathrm{kV}$ voltage range and spot size in the range of 3-5.

\section{Characterisation of polyelectrolyte}

FTIR was used to determine the functional groups in the polymer. The analysis was done using Bruker Vertex $80 \mathrm{v}$ with Attenuated Total Reflectance in transmittance mode. OPUS 7.0 software was used for the analysis, and the infrared spectroscopy was done from 400 to $4000 \mathrm{~cm}^{-1}$.
Table 1 Petrophysical properties of core plugs

\begin{tabular}{lcccccccccc}
\hline Core plug & 01 & 02 & 03 & 04 & 05 & 06 & 07 & 08 & 09 & 10 \\
\hline Length (cm) & 4.4 & 2.2 & 2.8 & 4.4 & 3.8 & 3.0 & 2.1 & 2.5 & 3.8 & 2.1 \\
Diameter (cm) & 2.2 & 2.5 & 2.2 & 2.2 & 2.2 & 2.2 & 2.2 & 2.2 & 2.2 & 2.2 \\
Porosity & 0.29 & 0.2 & 0.1 & 0.29 & 0.2 & 0.1 & 0.25 & 0.31 & 0.19 & 0.19 \\
Permeability (md)* & 145.8 & 162 & 293.1 & 298.15 & 97 & 293.1 & 230 & 228.4 & 97 & 215.3 \\
\hline
\end{tabular}

*Liquid permeability by brine

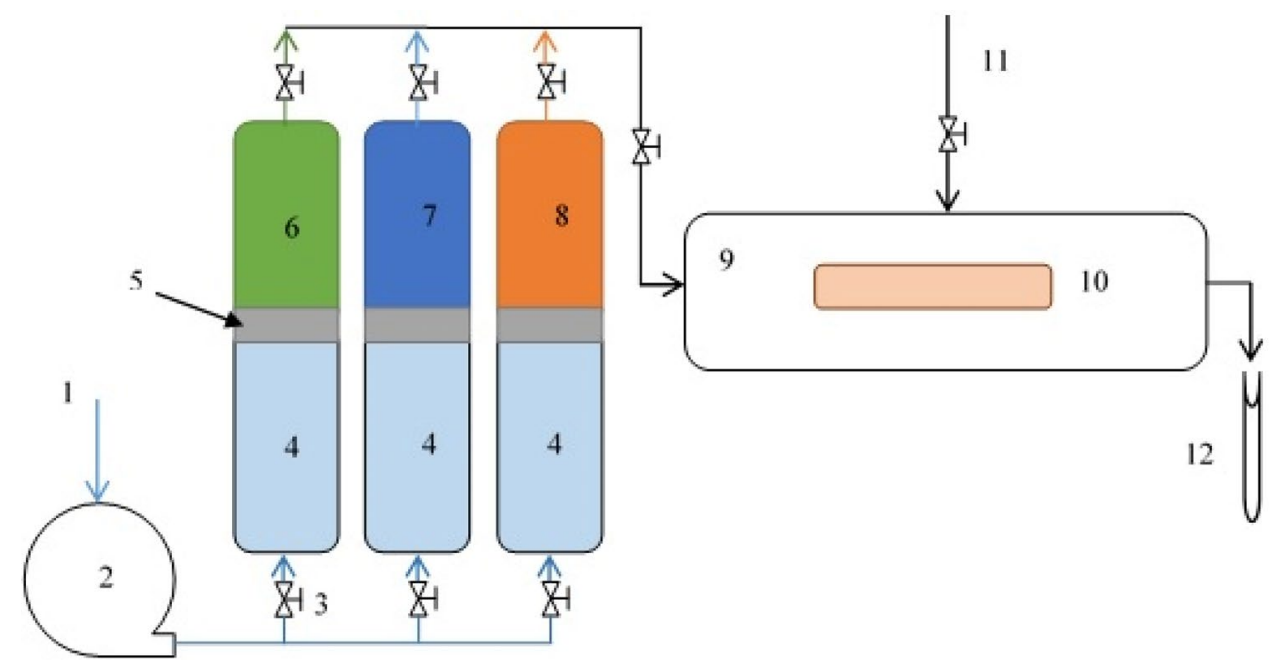

Fig. 1 Schematic of the core flooding apparatus (OFITE reservoir permeability tester). 1 Fluid supply, 2515 HPLC pump, 3 valves, 4 water, 5 drive piston, 6 crude oil, 7 brine, 8 polymer or nanocomposite, 9 Hassler cell holder, 10 core plug, 11 confining pressure, 12 test tube for effluent (Orodu et al. 2019)

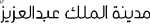

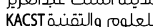




\section{Results and discussion}

\section{Viscosity profile of polyelectrolytes}

Comparing the viscosity profile of gum arabic and xanthan gum as presented in Fig. 2a, b shows a wide gap between both polyelectrolytes.

Also, the gum arabic exhibited shear-thinning behaviour but showed a near-Newtonian behaviour at higher shear rates. This is consistent with the research conducted by $\mathrm{Li}$ et al. (2009) and Sanchez et al. (2002), where gum arabic was reported to show both Newtonian and non-Newtonian behaviour at different conditions. Consequently, gum arabic had a viscosity of $250 \mathrm{cP}$ at $15 \mathrm{wt} \%$. This low viscosity of the gum arabic is attributed to the low molecular weight compared to other commonly used polymers and polyelectrolytes in EOR such as xanthan gum. Gum arabic has a molecular weight between 250,000 and 1,000,000 Daltons (Atgie 2018; Gashua et al. 2015). Thus, xanthan gum's molecular weight (XG) is approximately 10 times that of GA's. Hence, the wide margin in viscosity. The viscosity profile of XG at 0.1 $\mathrm{wt} \%$ is similar to that of GA at a weight concentration of $1 \mathrm{wt} \%$ in brine. Notwithstanding this, the emulsifying nature of GA makes it a candidate for EOR based on the investigation by Desplanques et al. (2012) that GA has emulsifying property compared to $\mathrm{XG}$ as investigated, while $\mathrm{XG}$ is more viscous than GA. This sees the combination of IFT reduction and partial modification of the displacing fluid viscosity to reduce mobility compared to waterflooding. In addition, though the viscosity of XG is 10 times that of GA, cost implications still favour GA as Orodu et al. (2019) reported the price of GA in Nigeria as USD $3.862 \mathrm{~kg}^{-1}$, while XG is USD $1210.7 \mathrm{~kg}^{-1}$ from Sigma-Aldrich.

\section{Viscosity profile of gum arabic at different temperatures}

Figure 3 shows the effect of temperature on the viscosity of GA at $0.4,0.5,1,5,10$ and $15 \%$ w/w, respectively. It was observed across all weight percentages that the viscosity of gum arabic reduced with temperature, with the highest and lowest viscosities obtained at 30 and $90{ }^{\circ} \mathrm{C}$, respectively.

At $0.4,0.5,1,5,10$ and $15 \% \mathrm{w} / \mathrm{w}$, the viscosities reduced by $56.7,41.2,25,30,31.8$ and $32.7 \%$, respectively, from 30 to $90{ }^{\circ} \mathrm{C}$ averaging a $36.2 \%$ decrease in viscosity. For temperature of $30-75^{\circ} \mathrm{C}$, the per cent reduction is 53.3 , $29.4,22.2,15.0,18.2$ and $22.4 \%$, respectively, while that of $50^{\circ} \mathrm{C}$ is $3.3,8.8,11.1,10.0,9.1$ and $10.2 \%$, respectively. All these reductions given above are at a shear rate of $10.21 \mathrm{~s}^{-1}$. This viscosity reduction is attributed to the weakening of the polyelectrolytes intermolecular bonds as the temperature increases, leading to lower viscosity. According to Choperena and Painter (2009), in the case of hydrogen bonds, as indicated by the FTIR spectrum, the adsorption coefficient changes significantly as the temperature increases, resulting directly in a reduction in the strength of the polymers hydrogen bond. Comparing this to the weight loss by the polyelectrolyte under high temperature (Fig. 4), gum arabic lost $9.1 \%$ of its weight at $90{ }^{\circ} \mathrm{C}$ due to moisture vaporisation and loss of suspended solids. However, at an average reservoir temperature of $75^{\circ} \mathrm{C}, \mathrm{GA}$ lost an average of $25.5 \%$ of its viscosity and $7.4 \%$ of its weight (Fig. 4). As the weight percentage increases, the viscosities also increase. However, the weight loss of XG is higher, showing lower thermal stability compared to GA. However, the extensive dataset of the rheological experiment, as presented in Sowunmi et al. (2020), shows marginal higher viscosity at $30-90{ }^{\circ} \mathrm{C}$ for $\mathrm{XG}$ over GA. This is not expected for the TGA result. A better explanation may be connected to the XG structure's rigidity and the higher $\mathrm{COO}^{-}$content leading to improved rheology despite its degradation.

\section{Effect of nanoparticle loading and type on gum arabic viscosity}

Figure 5a, b shows the effect of silica and alumina nanoparticle loading on the viscosity of gum arabic. As the nanoparticle was loaded into the polyelectrolyte, the viscosity was observed to increase as both nanoparticles' quantity
Fig. 2 Viscosity profile at different weight percentages and $30{ }^{\circ} \mathrm{C}$ a gum arabic, $\mathbf{b}$ xanthan gum
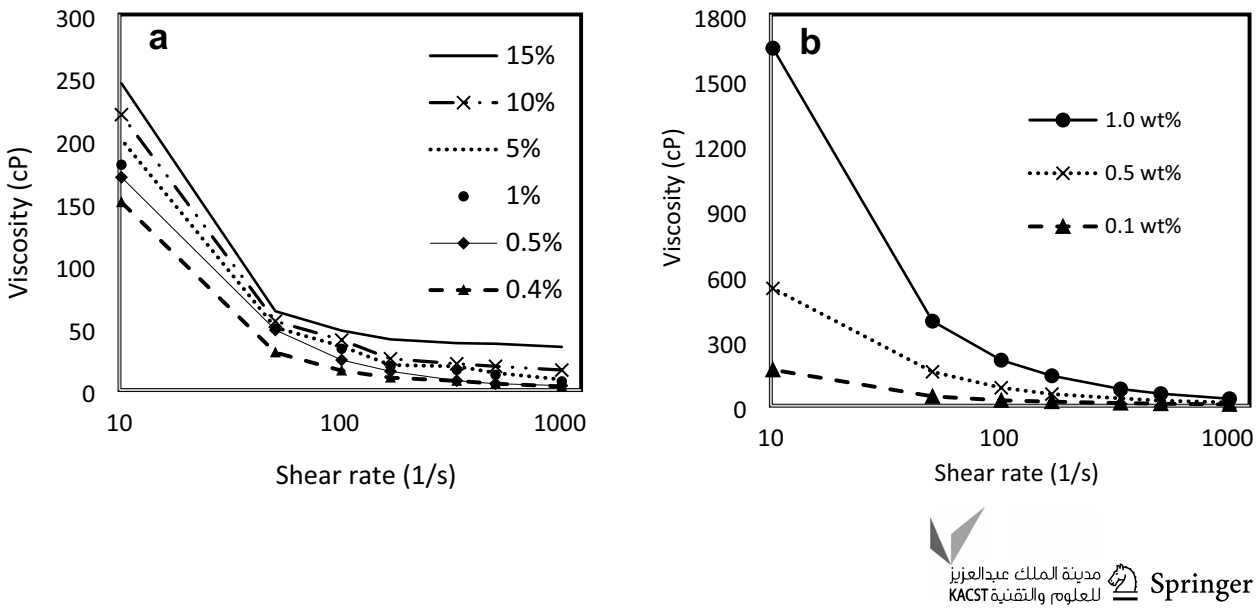
Fig. 3 Viscosities of $0.4,0.5$, $1.0,5.0,10.0$ and $15 \mathrm{wt} \%$ gum arabic at different temperatures
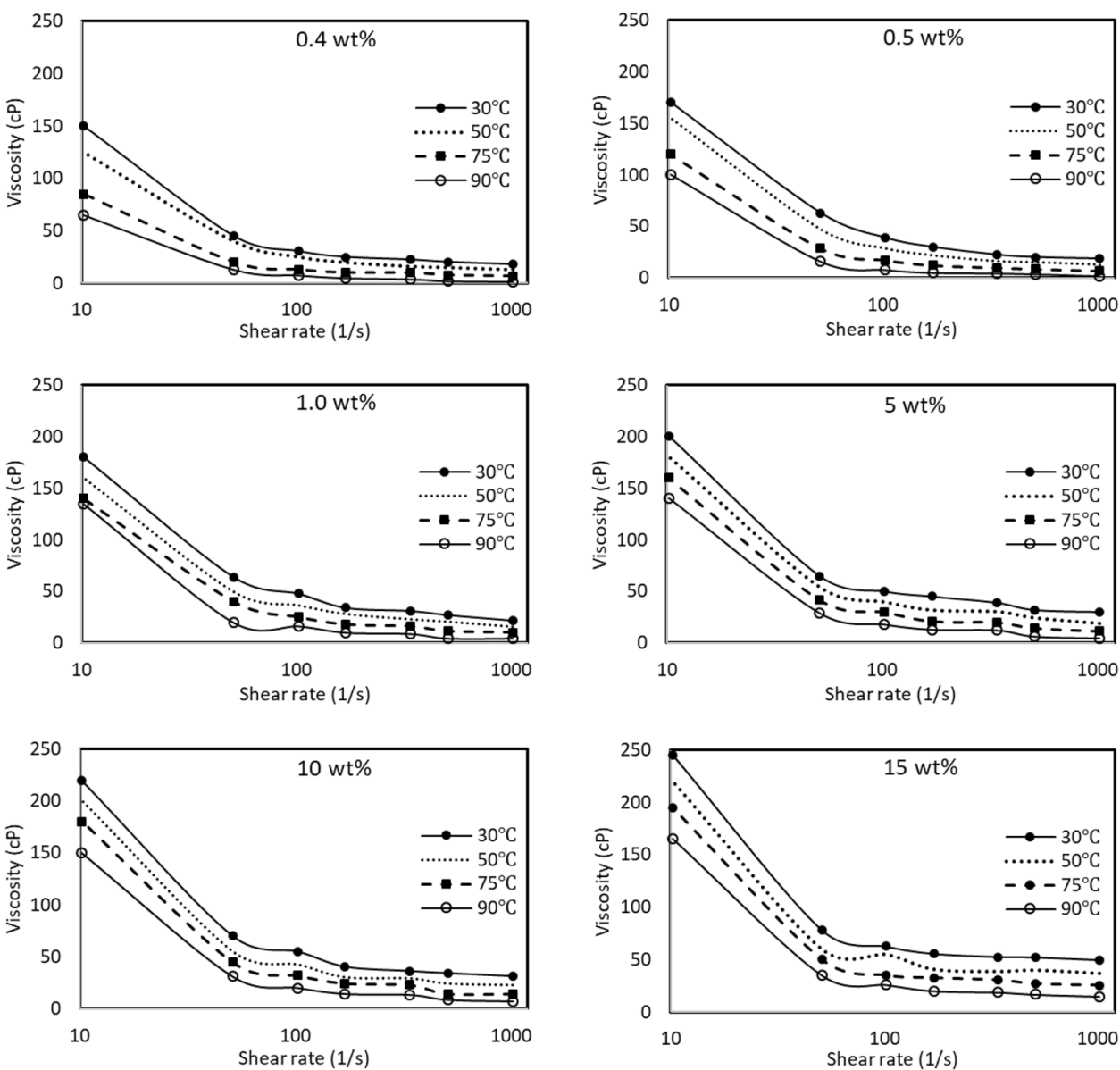

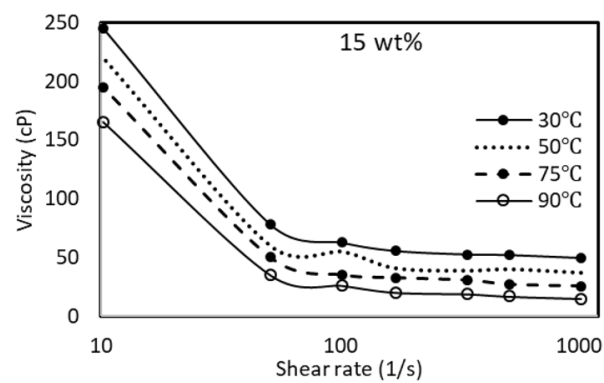

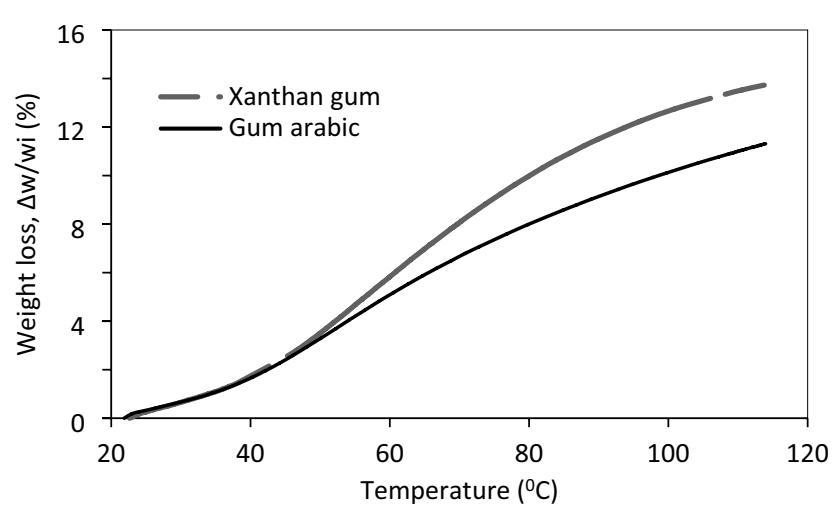

Fig. 4 TGA plot of gum arabic polymer

was increased. The loading of silica nanoparticle to $1 \mathrm{wt} \%$ increased the viscosities of $0.4,0.5,1,5,10$ and $15 \mathrm{wt} \%$ gum arabic by $21.3,15.3,11.1,20,30.9$ and $32.7 \%$, respectively, leading to an average viscosity increase of $21.9 \%$. The loading of alumina nanoparticle increased the viscosities of $0.4,0.5,1,5,10$ and $15 \mathrm{wt} \%$ gum arabic by $28.3,22.5$, $19.4,20,36.4$ and $32.7 \%$, respectively, leading to an average viscosity increase of $26.5 \%$. Alumina nanoparticle provided a greater increase in the viscosity of gum arabic than silica nanoparticles (Fig. 5c). The implication for sweep efficiency in EOR is that a nanocomposite containing alumina nanoparticles will outperform a nanocomposite containing silica nanoparticles since alumina will provide greater increase in the viscosity of gum arabic than silica nanoparticles, and this is beside the microscopic interactions of the nanoparticle in EOR.

\section{Core flooding}

\section{Polymeric solution flooding}

Though a wide range of gum arabic (GA) concentrations was investigated for its rheological property, the low concentration was subsequently adopted for core flooding. The reason for this is to prevent/avoid pore throat blockage of the porous media. GA is known for self-aggregation, which is the key to its emulsifying property's long-term stability due to arabinogalactan protein (AGP) (Li et al. 2009; Xiang et al. 2015). And, the hydrodynamic size of GA increases with concentration in water (Isobe et al. 2020; Li et al. 2009). This explains why blockage is possible. In as much that, the relatively similar magnitude in viscosity readings of different 

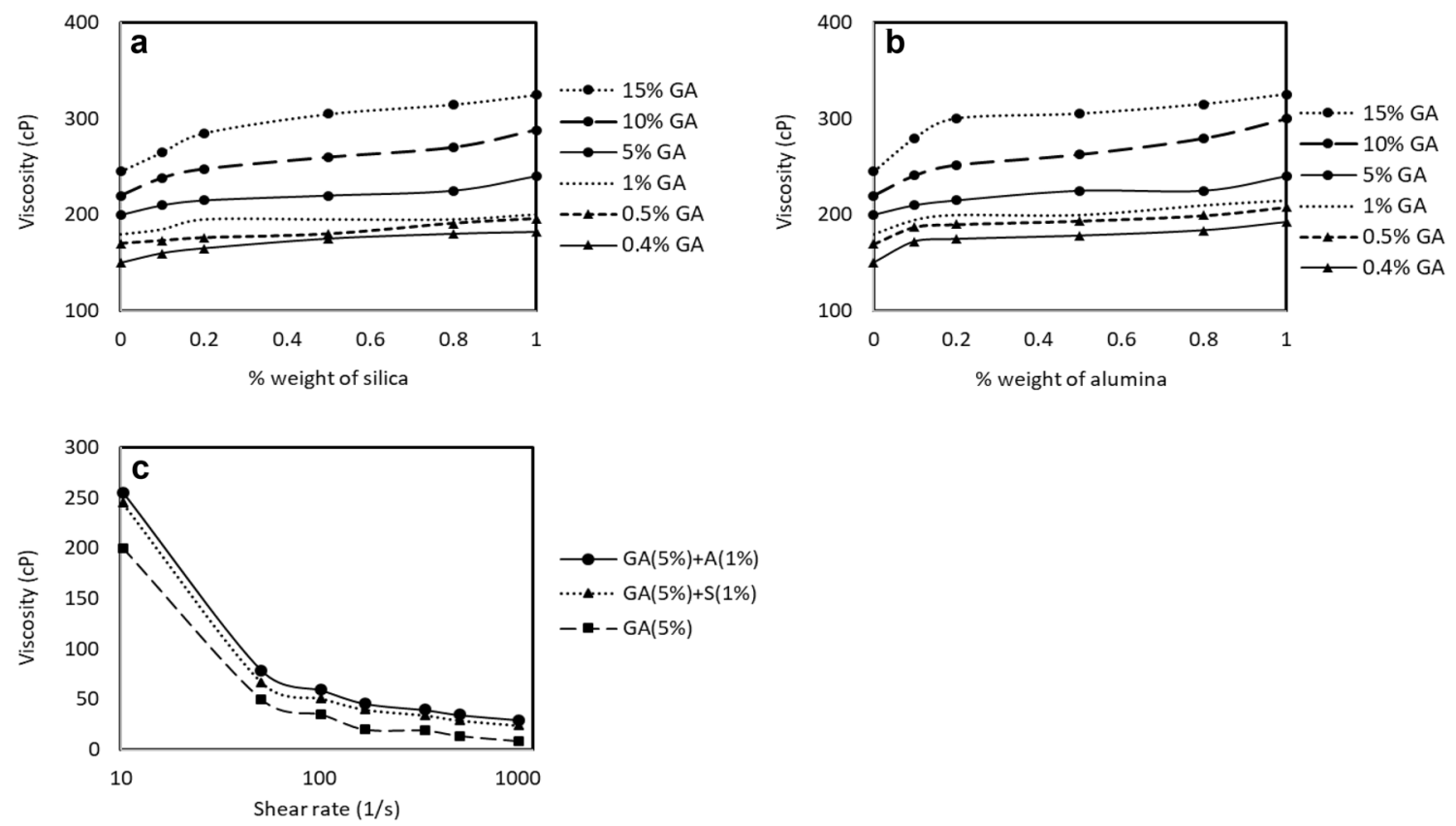

Fig. 5 a-c Viscosity of gum arabic vs. silica loading; viscosity of gum arabic vs. alumina loading and the effect of nanoparticle types on viscosities of the three fluids

Table 2 Incremental recovery for gum arabic and xanthan gum at different concentrations

\begin{tabular}{|c|c|c|c|c|}
\hline \multirow[t]{3}{*}{ Flood type } & \multicolumn{2}{|c|}{ Core plug-01 } & \multicolumn{2}{|c|}{ Core plug-04 } \\
\hline & \multicolumn{2}{|c|}{ Gum arabic-GA } & \multicolumn{2}{|c|}{ Xanthan gum-XG } \\
\hline & Conc. $\%$ & $\begin{array}{l}\text { Incremental } \\
\text { recovery \% }\end{array}$ & Conc. $\%$ & $\begin{array}{l}\text { Incremental } \\
\text { recovery } \%\end{array}$ \\
\hline Waterflood & 0 & 38.0 & 0 & 45.9 \\
\hline Slug 1: polymeric & 0.4 & 4.0 & 0.1 & 4.9 \\
\hline Slug 2: polymeric & 0.5 & 4.0 & 0.3 & 4.8 \\
\hline Slug 3: polymeric & 1.0 & 6.0 & 0.5 & 7.2 \\
\hline Total & & 52.0 & & 62.8 \\
\hline
\end{tabular}

concentrations investigated in this study (see Fig. 2) adds on the requirement for low concentration flooding.

Table 2 depicts total oil recovery from only GA and XG flooding without NP for core plug-01 (Table 2 for GA) and core plug-04 (Table 2 for XG). The flooding sequence was first by waterflooding till constant consecutive oil recovery and subsequently followed by three slugs of polymeric solution (see Fig. 6a for GA flooding performance). The polymeric slugs are concentrations of $0.4,0.5$ and $1.0 \mathrm{wt} \%$, respectively, for GA (Column-2 of Table 2) and 0.1, 0.3 and $0.5 \mathrm{wt} \%$, respectively, for XG (Column-4 of Table 2). Column- 3 and Column- 5 of Table 2 present the performance of incremental oil recovery for both polymeric solutions. The magnitude of oil recovery is not surprising as attributed to movable oil based on further mobility ratio reduction of displacing fluid and IFT with increasing polymer concentration. Mobility ratio reduction and comparison of both polymeric solutions are effectively captured by in situ viscosity, as presented in Table 3. The values of ' $K$ ' and ' $n$ ' in the table are based on the power-law regression model fitting of 7 experimental data points from the 8 test speeds of the OFITE- 800 Viscometer for each polymer concentration. In situ viscosity tied to core flooding rate (shear rate) increases with biopolymer concentration increase. Table 2 shows comparable incremental recovery magnitude for GA and XG. However, in situ viscosity for XA is multiple of 3-5 of GA, translating to increased capillary number assuming constant IFT. The interpretation is mobility rate only; it does not account for the performance of GA if optimal viscosity has not been attained and in the absence of coreflooding differential pressure profile.

Sequential flooding with increasing polymer concentration accompanied by incremental oil recovery can also be accounted for due to mobilising trapped residual oil. Earlier work on GA flooding by Orodu et al. (2019) showed this for the recovery of $34.97^{\circ}$ API oil for Darcy velocity of $0.0465 \mathrm{~cm} \mathrm{~min}^{-1}(2.2 \mathrm{ft} / \mathrm{D})$, where GA flooding reduced residual oil by 5.88 saturation-percentage points (reduction by 0.02 saturation points), for this study, with a flooding rate of $0.1315 \mathrm{~cm} \mathrm{~min}^{-1}(6.21 \mathrm{ft} / \mathrm{D})$, is residual oil mobilised by relatively high flooding rate or IFT reduction?

Wang et al. (2000) and Wang et al. (2001) elucidated through micromodel the mechanisms of residual oil reduction by polymers. The "pulling" or "dragging" and 
Fig. 6 Oil recovery at different weight percentages of a gum arabic [core plug-01], b gum arabic-silica nanocomposite [core plug-02] and $\mathbf{c}$ gum arabic-alumina nanocomposite [core plug-03]
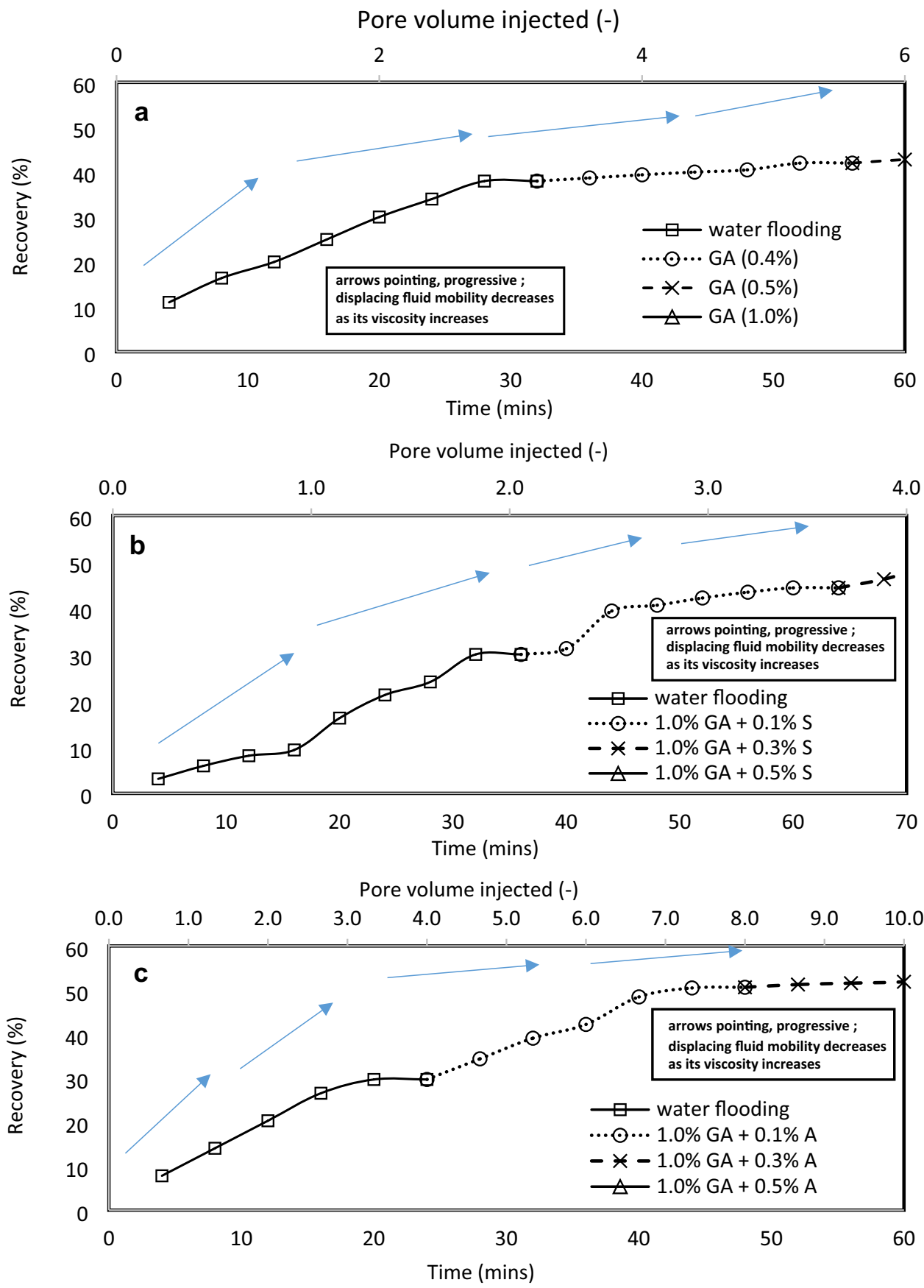

"stripping" effect due to the viscoelastic nature of HPAM alluded to this. In this study, the average incremental recovery by GA and XA is 4.6 and $5.6 \%$, respectively, after waterflooding to residual oil saturation (Sor) and not distant from Wang et al. (2000) 6\% and above. Hence, what mechanism is at play for GA and XA? As earlier stated in Sect. 2.4, viscous contribution to viscosity outplays the elastic contribution for GA at a shear rate greater than $10 \mathrm{~s}^{-1}$, and in situ shear rate is about $480 \mathrm{~s}^{-1}$ for Darcy velocity of $6.21 \mathrm{ft} / \mathrm{D}$ (flooding rate of $0.5 \mathrm{~cm}^{3} \mathrm{~min}^{-1}$ ). So, is IFT responsible as expected or, as stated by Seright et al. (2018), that Sor reduction is due to a relatively high injection rate and capillary number?

To further bolster the increase in recovery with increased concentration of GA, the experimental investigation by Isobe et al. (2020) confirmed IFT reduction with increasing GA concentration. The authors likewise presented results of rapid IFT reduction with time, indicating a sudden decrease at 500 secs and 1000 secs residence time for GA concentration of $20 \%$ and $0.5 \mathrm{wt} \%$, respectively, using vegetable oil, while 20-30 secs for vegetable oil and dodecane at a GA concentration of $5 \mathrm{wt} \%$. This is within the resident time 
Table 3 In situ rheology of gum arabic and xanthan gum

\begin{tabular}{|c|c|c|c|c|c|c|c|c|}
\hline \multirow[t]{2}{*}{$\begin{array}{l}\text { Polymer } \\
\text { Conc. wt\% }\end{array}$} & \multirow[t]{2}{*}{$\begin{array}{l}\text { Regression } \\
\text { Coef. } R^{2}\end{array}$} & \multirow[t]{2}{*}{$n$} & \multirow[t]{2}{*}{$K$} & \multirow[t]{2}{*}{$\begin{array}{l}\text { Core } \\
\text { plug \# }\end{array}$} & \multirow{2}{*}{$\begin{array}{l}\text { Core plug } \\
\text { area } \\
A\left(\mathrm{~cm}^{2}\right)\end{array}$} & \multirow{2}{*}{$\begin{array}{l}\text { Flow rate } \\
Q\left(\mathrm{~cm}^{3} \mathrm{~min}^{-1}\right)\end{array}$} & \multirow{2}{*}{$\begin{array}{l}\text { Shear rate } \\
\text { [Eq. (1)] } \\
\gamma\left(\mathrm{s}^{-1}\right)\end{array}$} & \multirow{2}{*}{$\begin{array}{l}\text { Viscosity } \\
{[\text { Eq. (2)] }} \\
\mu(\mathrm{cp})\end{array}$} \\
\hline & & & & & & & & \\
\hline XG 0.1 & 0.9995 & $0.290 \pm 0.028$ & $754.14 \pm 1.15$ & 04 & 3.80 & 0.5 & 478.31 & 9.44 \\
\hline XG 0.3 & 0.9966 & $0.230 \pm 0.027$ & $2360.5 \pm 1.15$ & 04 & 3.80 & 0.5 & 484.76 & 20.19 \\
\hline XG 0.5 & 0.9997 & $0.210 \pm 0.015$ & $3316.5 \pm 1.08$ & 04 & 3.80 & 0.5 & 487.40 & 24.96 \\
\hline GA 0.4 & 0.9956 & $0.162 \pm 0.041$ & $882.1 \pm 1.24$ & 01 & 3.80 & 0.5 & 708.01 & 3.61 \\
\hline GA 0.5 & 0.9984 & $0.126 \pm 0.028$ & $1340.8 \pm 1.15$ & 01 & 3.80 & 0.5 & 719.03 & 4.27 \\
\hline GA 1.0 & 0.9952 & $0.315 \pm 0.034$ & $793.61 \pm 1.19$ & 01 & 3.80 & 0.5 & 680.79 & 9.10 \\
\hline
\end{tabular}

GA Gum arabic, $X G$ xanthan gum, Conc. concentration in weight $\%, n$ power-law exponent, $K$ consistency index are regressed values based on the reduced Carreau model [Eq. (4)] and applied in Eqs. (1) and (2)

of the coreflooding experiment carried out in this study, of which the average residence time is $1200 \mathrm{~s}$.

In terms of recovery performance, Eiroboyi et al. (2019) applied GA at $0.5 \mathrm{wt} \%$ to recover heavy oil $\left(\mathrm{API}^{\circ} 18.89\right.$; $54.9 \mathrm{cp})$ after waterflooding in an oil-saturated sand pack. Displacement achieved a gradual recovery of $26.7 \%$ for GA, while for this study, a cumulative incremental recovery of $16 \%$ for a consolidated core plug. With the different porous media, crude oil and flooding sequence, GA concentration affects the magnitude of oil recovery. Abdulraheem et al. (2018) study on heavy oil-saturated glass beads resulted in an incremental recovery of $28.81 \%$ by GA flooding. The modification of GA further increased recovery.

\section{NP-polymeric solution flooding}

The magnitude of incremental oil recovery for Slug-1 of NPpolymeric, as seen in Tables 4, 5, 6 and 7, is relatively high. Figure $6 \mathrm{~b}$, c showcases this trend for NP-GA-polymeric flood. Furthermore, polymer concentration seems independent of the performance. Table 4 represents GA concentration of 0.5 and $1.0 \mathrm{wt} \%$ for Table 5, whereas for XG, Tables 6 and 7 are for 0.1 and $0.5 \mathrm{wt} \%$, respectively. Similar oil recovery performance accounts for both silica and alumina nanoparticles for these two scenarios of NP-GA and NP-XG polymeric solution. However, polymer concentration may not be vital for NP-GA-polymeric solution; it clearly shows a trend for NP-XG-polymeric solution as higher concentration resulted in higher oil recovery. In Fig. 2a, b, the rheology of GA and XG, respectively, at different concentrations, portrays the influence of viscosity and the subsequent effect on oil recovery.

XG-polymeric solution outperforms GA-polymeric solution at a similar concentration. Still, when viscosity is identical as the case of $\mathrm{XG}$ at $0.1 \mathrm{wt} \%$ and GA at $1.0 \mathrm{wt} \%$, the performance is identical, as seen in Tables 5 and 6 for NP-polymeric solutions. $\mathrm{GA}-\mathrm{SiO}_{2}$ and $\mathrm{XG}-\mathrm{SiO}_{2}$ nanocomposite resulted in slightly lower oil recovery than $\mathrm{GA}-\mathrm{Al}_{2} \mathrm{O}_{3}$ and $\mathrm{XG}-\mathrm{Al}_{2} \mathrm{O}_{3}$ nanocomposites. Alumina NP has been confirmed repeatedly as superior to silica NP based on its higher surface-active nature. The preferential adoption of silica NP is due to its abundance in nature.

The impact of nanoparticles in the polymer is not all about viscosity enhancement but, to an extent, IFT reduction, leading to a further increase in movable oil. Isobe et al. (2020) reported through experimental investigation, IFT reduction of dodecane with $5.0 \mathrm{wt} \%$ GA from about $37-18 \mathrm{mN} \mathrm{m}^{-1}$ within $100 \mathrm{~s}$. The time at which this occurs is achievable in coreflood experiments to experience IFT reduction. On addition of unmodified hydrophilic silica NP $(15 \mathrm{~nm})$ to XG, Saha et al. (2018) reported IFT reduction for the nanocomposite/crude oil $\left(21.2^{\circ} \mathrm{API}\right) /$ synthetic formation water from $17.8 \mathrm{mN} \mathrm{m}^{-1}$ at $0 \% \mathrm{NP}$ to $10.85,8.67$ and $8.54 \mathrm{mN} \mathrm{m}^{-1}$ for NP concentration of $0.1,0.3$ and 0.5 $\mathrm{wt} \%$, respectively, at $30{ }^{\circ} \mathrm{C}$. Reservoir condition temperature results in lower IFT. Furthermore, the contact angle was lower for the nanocomposite than only XG; this further reduced with an increase in residence time. The pressure drop profile clearly showed a continuous increase during the chemical flooding process.

Rashid (2019) investigated extensively hydrophilic silica NP $(20 \mathrm{~nm})$ and gum arabic blends at varying salinity (0, $0.5,0.1$ and $0.15 \mathrm{wt} \% \mathrm{NaCl}$ ) and temperature. In crude oil of $25.7^{\circ} \mathrm{API}$, that is medium oil. Though Rashid's study shows IFT reduced by different combinations of GA and $\mathrm{SiO}_{2}-\mathrm{NP}$ concentrations, the magnitude at $30^{\circ} \mathrm{C}$ is marginal and reduces considerably with an increase in temperature. Hence, from Saha et al. (2018) and Rashid (2019), IFT can be inferred to take the backseat or minimal influence in improved oil recovery for ambient temperature investigated in this study. The effect of IFT shall be pronounced at reservoir conditions.

The incremental oil recovery performance encountered by the experimental study in this work is comparable to other results. First slug recovery by nano-polymeric solution is within $10.73-20.9 \%$, ignoring the isolated case of

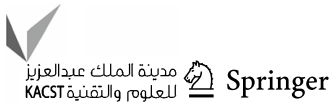


Table 4 Incremental recovery for nanocomposites at 0.5 wt $\%$ gum arabic and different nanoparticle concentrations of silica and alumina

Table 5 Incremental recovery for nanocomposites at 1.0 wt $\%$ gum arabic and different nanoparticle concentrations of silica and alumina

Table 6 Incremental recovery for nanocomposites at $0.1 \mathrm{wt} \%$ xanthan gum and different nanoparticle concentrations of silica and alumina

\begin{tabular}{|c|c|c|c|c|}
\hline \multirow[t]{2}{*}{ Flood type } & \multicolumn{2}{|l|}{ Core plug-02 } & \multicolumn{2}{|l|}{ Core plug-03 } \\
\hline & $\begin{array}{l}\mathrm{SiO}_{2} \text {-NP Conc. } \\
\%\end{array}$ & $\begin{array}{l}\text { Incremental recov- } \\
\text { ery } \%\end{array}$ & $\begin{array}{l}\mathrm{Al}_{2} \mathrm{O}_{3} \text {-NP Conc. } \\
\%\end{array}$ & $\begin{array}{l}\text { Incremental } \\
\text { recovery \% }\end{array}$ \\
\hline Waterflood & 0 & 29.0 & 0 & 26.9 \\
\hline Slug 1: NP-polymeric Soln & 0.1 & 15.6 & 0.1 & 19.4 \\
\hline Slug 2: NP-polymeric Soln & 0.3 & 3.4 & 0.3 & 3.1 \\
\hline Slug 3: NP-polymeric Soln & 0.5 & 4.4 & 0.5 & 5.2 \\
\hline Total & & 52.4 & & 54.6 \\
\hline
\end{tabular}

\begin{tabular}{llllll}
\hline Flood type & \multicolumn{2}{l}{ Core plug-05 } & & \multicolumn{2}{l}{ Core plug-06 } \\
\cline { 2 - 3 } \cline { 5 - 6 } & $\begin{array}{l}\mathrm{SiO}_{2} \text {-NP Conc. } \\
\%\end{array}$ & $\begin{array}{l}\text { Incremental recov- } \\
\text { ery } \%\end{array}$ & $\begin{array}{l}\mathrm{Al}_{2} \mathrm{O}_{3} \text {-NP Conc. } \\
\%\end{array}$ & $\begin{array}{l}\text { Incremental } \\
\text { recovery } \%\end{array}$ \\
\hline Waterflood & 0 & 30.0 & 0 & 29.7 \\
Slug 1: NP-polymeric Soln & 0.1 & 14.4 & 0.1 & 20.9 \\
Slug 2: NP-polymeric Soln & 0.3 & 6.2 & 0.3 & 2.7 \\
Slug 3: NP-polymeric Soln & 0.5 & 4.1 & & 0.5 & 3.3 \\
Total & & 54.7 & & 56.6 \\
\hline
\end{tabular}

\begin{tabular}{|c|c|c|c|c|}
\hline \multirow[t]{2}{*}{ Flood type } & \multicolumn{2}{|l|}{ Core plug-07 } & \multicolumn{2}{|l|}{ Core plug- 08} \\
\hline & $\begin{array}{l}\mathrm{SiO}_{2} \text {-NP Conc. } \\
\%\end{array}$ & $\begin{array}{l}\text { Incremental recov- } \\
\text { ery } \%\end{array}$ & $\begin{array}{l}\mathrm{Al}_{2} \mathrm{O}_{3} \text {-NP Conc. } \\
\text { - }\end{array}$ & $\begin{array}{l}\text { Incremental } \\
\text { recovery \% }\end{array}$ \\
\hline Waterflood & 0 & 35.00 & 0 & 30.6 \\
\hline Slug 1: NP-polymeric Soln & 0.1 & 10.73 & 0.1 & 17.6 \\
\hline Slug 2: NP-polymeric Soln & 0.3 & 3.29 & 0.3 & 6.8 \\
\hline Slug 3: NP-polymeric Soln & 0.5 & 4.64 & 0.5 & 3.3 \\
\hline Total & & 53.66 & & 58.3 \\
\hline
\end{tabular}

Table 7 Incremental recovery for nanocomposites at $0.5 \mathrm{wt} \%$ xanthan gum and different nanoparticle concentrations of silica and alumina

\begin{tabular}{|c|c|c|c|c|}
\hline \multirow[t]{2}{*}{ Flood type } & \multicolumn{2}{|l|}{ Core plug-09 } & \multicolumn{2}{|l|}{ Core plug-10 } \\
\hline & $\mathrm{SiO}_{2}$-NP Conc. $\%$ & Incremental recovery $\%$ & $\mathrm{Al}_{2} \mathrm{O}_{3}$-NP Conc. $\%$ & Incremental recovery $\%$ \\
\hline Waterflood & 0 & 18.8 & 0 & 33.9 \\
\hline $\begin{array}{l}\text { Slug 1: NP-polymeric } \\
\text { Soln }\end{array}$ & 0.1 & 35.4 & 0.1 & 20.9 \\
\hline $\begin{array}{l}\text { Slug 2: NP-polymeric } \\
\text { Soln }\end{array}$ & 0.3 & 7.3 & 0.3 & 6.5 \\
\hline $\begin{array}{l}\text { Slug 3: NP-polymeric } \\
\text { Soln }\end{array}$ & 0.5 & 6.5 & 0.5 & 11.3 \\
\hline Total & & 68.2 & & 72.6 \\
\hline
\end{tabular}

GA Gum arabic, $X G$ xanthan gum, Conc. concentration in weight $\%, N P$ nanoparticle

$35.4 \%$. This is compared to the reviewed works by Corredor et al. (2019b), in which medium oil recovery was within
6.0-16.3\%. The nanocomposites in these instances were hydrolysed polyacrylamide and XG nanocomposites. 

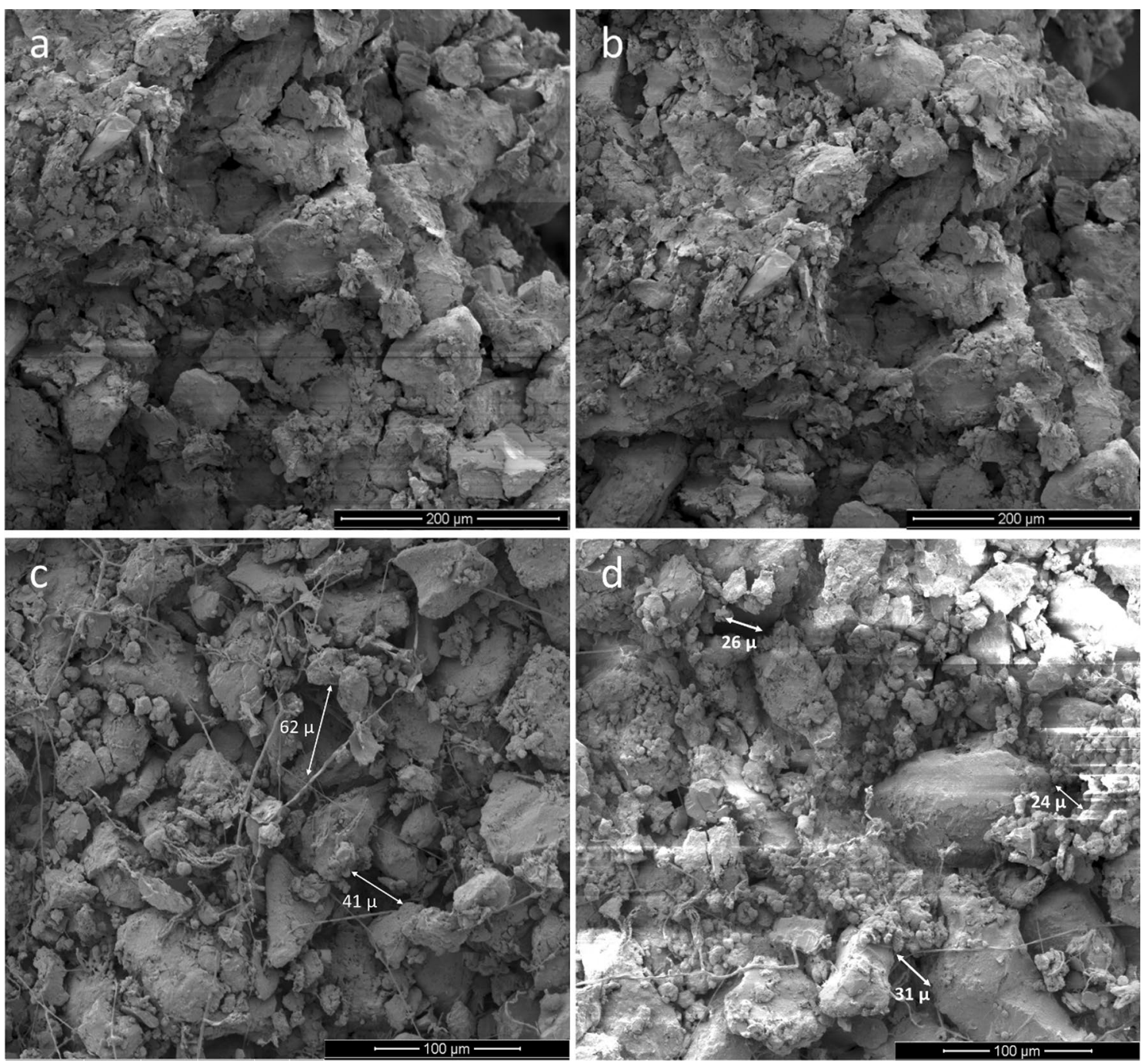

Fig. 7 SEM micrographs of core plugs pre- and post-nanocomposite flooding. a Pre-gum arabic-silica flooding; b post-gum arabic-silica flooding; c pre-gum arabic-alumina flooding; d post-gum arabic-alumina flooding

\section{Permeability impairment of core plugs}

Figure 7 shows sets of SEM results for gum arabic-silica nanocomposites (Fig. 7a, b) and gum arabic-alumina nanocomposites (Fig. 7c, d) before and after the core flooding. The micrographs revealed some amount of formation damage in the core plugs by injecting nanocomposites. Figure 7c, $\mathrm{d}$ shows the sizes of some of the identified pore throats in the core plugs. What is observed is that the identified pore throats in the pre-flooding core plug are larger than those in the post-flooding core plugs. The smaller pore throat sizes observed result from fines migration and the entrapment of the nanocomposites within the matrix of the core plugs.

The polymer nanocomposite or polymer nanohybrid mixes the following in a dispersed solution: polymer solution; nanoparticles (NP); and polymer adsorbed on NP, i.e. polymer-nano. As a consequence of GA's surface-active nature, its presence exists in the oil-water interface. Since the significant mechanisms of polymer retention are mechanical entrapment and rock-adsorption, these are considered critical to formation impairment. GA is known for selfaggregation leading to increased hydrodynamic size and may be trapped in the pore throat depending on its size in relation to the porous media ( $\mathrm{Li}$ et al. 2009; Xiang et al. 2015; Ido et al. 2008). The poor long period of stability of GA in the oil-water interface is due to this self-aggregation. GA is also a reducing sugar (Roque and Wilson 2007); therefore, the reason for the link of silica nanoparticle to it and the weak improved stability of the polymeric solution. Steric forces may be the reason for the stability of NP in GA solution as long-chain biopolymer and synthetic does, according to ShamsiJezeyi et al. (2014) and polyelectrolyte-coated polymeric nanoparticle (Bagaria et al. 2013; Yu et al. 2010). Hence, the likely minimal adsorption of NP on the rock,

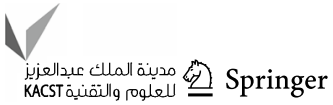




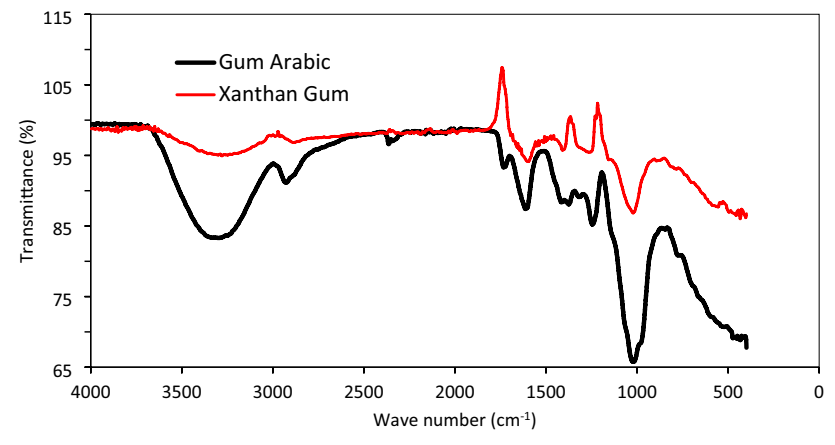

Fig. 8 FTIR spectrum analysis of gum arabic

though opposite charge between the polymer and rock, in conjunction with clay minerals in the rock may result in polymer deposition and adsorption. Issues such as this depend on $\mathrm{pH}$ and salinity that affect and swing the possibility of $\mathrm{NP}$ and polymer attachment on the rock.

The mineral content of the rock core plug samples being sandstone (silica) + clay is responsible for the interaction with the polymer, GA. Attachment to silica is due to the silanol group, controlled by $\mathrm{pH}$. The focus here is now on clay minerals. For clay, kaolinite is the primary mineral in the Niger Delta sandstone of the Agbada Formation (John 2017; Odigi 1994; Lambert-Aikhionbare and Shaw 1982). The sheet-like clay complex content, $\mathrm{Al}^{3+}+\mathrm{O}^{2-}$ and $\mathrm{OH}^{-}$, and $\mathrm{Si}^{4+}+\mathrm{O}^{2+}$ and $\mathrm{OH}^{-}$are the source of link for the GA carboxyl and hydroxyl groups. Sorbie (1991) argued that polymer's access to bound clay in the sandstone is limited against loose clay literature for adsorption test. However, Niger Delta sandstone's friable nature with fine migration issues (Odigi 1994; Lambert-Aikhionbare and Shaw 1982) consequently increases polymer contact with clay minerals during core flooding experiments and fluid flow in sandstone reservoirs.

\section{Characterisation of polyelectrolyte}

The strong adsorption peak of $3313 \mathrm{~cm}^{-1}$ (the stretch of $3000-3600$ ) and $1020 \mathrm{~cm}^{-1}$ in Fig. 8 defines the functional groups of $-\mathrm{OH}$ and $\mathrm{C}-\mathrm{O}$, respectively, in GA. And, 1409 and $1604 \mathrm{~cm}^{-1}$ is the functional group $\mathrm{C}=\mathrm{O}$. The shape of the FTIR spectra confirms gum arabic as in Bhakat et al. (2018), Hamidi et al. (2020), and Yao et al. (2021). The hydroxyl group in XG is less strong than in GA, hence higher absorption of GA to sandstone by hydrogen bond and higher chemical stability to oxygen attack and other contaminants, also, less viscosifying power (Sheng 2011). In addition, these functional groups explain the link with the surface hydroxyl group of nanoparticles.

\section{Conclusion}

A natural state polyelectrolyte, gum arabic (GA) and its nanocomposite were evaluated for enhanced oil recovery based on the mechanisms responsible for oil displacement, the magnitude of incremental oil recovery and polymer nature. Conclusions are now drawn from the experimental test, core flooding, rheology and characterisation study compared to a commercial and widely applied polyelectrolyte, xanthan gum (XG).

- $\mathrm{XG}$ proved to be a better viscosifying agent than GA, with $1.0 \mathrm{wt} \%$ of GA in polymeric solutions having a similar viscosity profile to $0.1 \mathrm{wt} \% \mathrm{XG}$. This difference is primarily due to the lower molecular weight of GA.

- While nanoparticle (NP) improved nanocomposite viscosity by an average of $20 \%$, only this does not account for the improved recovery of oil. Further reduction in interfacial tension and the synergistic nature of NP mechanism for displacement is responsible. Confirmation of this is similar to incremental oil recovery of XG and GA nanocomposite, irrespective of polymer concentration in the nano-polymeric solution.

- GA has higher thermal tolerance compared to XG from the thermogravimetric analysis. This expectation did not play out in GA's thermal stability as the decline in viscosity with temperature is higher than $\mathrm{XG}$. The rigid nature of XG molecules may be responsible for this and lesser absorbance of $-\mathrm{OH}$ group in the polysaccharide than GA. Similarly, the -OH group may boost the polymer's adsorption on sandstone, depending on $\mathrm{pH}$.

- The surface-active superiority nature of alumina NP over silica NP achieved slightly higher recovery, as seen in literature; this is widely known. However, silica NP is in abundance.

- Unlike the influence of viscoelastic polymers in reducing residual oil saturation, for polyelectrolytes, especially gum arabic, it can be attributed to its surface-active nature.

Acknowledgements The authors thank Covenant University management for the experimental facilities utilised for the research.

Funding Covenant University Centre for Research, Innovation and Discovery (CUCRID) supported the publication of this article.

\section{Declarations}

Conflict of interest The authors declare that they have no conflict of interest.

Ethical approval The authors declare that the experiments conducted neither contain any human participant nor animal. 
Open Access This article is licensed under a Creative Commons Attribution 4.0 International License, which permits use, sharing, adaptation, distribution and reproduction in any medium or format, as long as you give appropriate credit to the original author(s) and the source, provide a link to the Creative Commons licence, and indicate if changes were made. The images or other third party material in this article are included in the article's Creative Commons licence, unless indicated otherwise in a credit line to the material. If material is not included in the article's Creative Commons licence and your intended use is not permitted by statutory regulation or exceeds the permitted use, you will need to obtain permission directly from the copyright holder. To view a copy of this licence, visit http://creativecommons.org/licenses/by/4.0/.

\section{References}

Abdulraheem M, Hamisu T, Abdullahi G, Oluwaseun T, Kelani B, Mohammed I, Olalekan O (2018) Comparative analysis on rate dependent polymer flooding using bio and synthetic polymers. In: Paper presented at the SPE Nigeria annual international conference and exhibition, Lagos, Nigeria

Akbari S, Mahmood SM, Tan IM, Ghaedi H, Ling OL (2017) Assessment of polyacrylamide based co-polymers enhanced by functional group modifications with regards to salinity and hardness. Polymers (basel) 9:1-16

Atgie M (2018) Composition and structure of gum arabic in solution and at oil-water. Université de Toulouse, France. https://oatao. univ-toulouse.fr/20871/1/ATGIE_Marina.pdf

Austad T, RezaeiDoust A, Puntervold T (2010) Chemical mechanism of low salinity water flooding in sandstone reservoirs. Society of Petroleum Engineers (SPE)

Bagaria HG, Neilson BM, Worthen AJ, Xue Z, Yoon KY, Cheng V, Lee JH, Velagala S, Huh C, Brryant GL, Bielawski CW, Johnston KP (2013) Adsorption of iron oxide nanoclusters stabilised with sulfonated copolymers on silica in concentrated $\mathrm{NaCl}$ and Cacl 2 brine. J Colloid Interface Sci 398:217-226

Behzadi A, Mohammadi A (2016) Environmentally responsive surface-modified silica nanoparticles for enhanced oil recovery. $\mathrm{J}$ Nanopart Res 18:266

Bhakat D, Barik P, Bhattacharjee A (2018) Electrical conductivity behaviour of Gum Arabic biopolymer-Fe3O4 nanocomposites. J Phys Chem Solids 112(2018):73-79

Budd P (1989) Polyelectrolytes comprehensive polymer science and supplements, 2nd edn. Pergamon, UK, pp 215-230

Cannella WJ, Huh C, Seright RS (1988) Prediction of xanthan rheology in porous media. In: Paper SPE 18089 presented at the SPE annual technical conference and exhibition, Houston, TX, 2-5 October (1988)

Chen L (2015) Emulsifiers as food texture modifiers Modifying Food Texture, vol 1. Elsevier, USA, pp 27-49

Chen Q, Wang Y, Lu Z (2013) Thermoviscosifying polymer used for enhanced oil recovery: rheological behaviours and core flooding test. Polym Bull 70:391-401

Choperena A, Painter P (2009) Hydrogen bonding in polymers: effect of temperature on the $\mathrm{OH}$ stretching bands of poly(vinylphenol). Macromolecules 42(16):6159-6165

Corredor L, Husein M, Maini B (2019a) Effect of hydrophobic and hydrophilic metal oxide nanoparticles on the performance of xanthan gum solutions for heavy oil recovery. Nanomaterials 9(1):94-107

Corredor L, Husein M, Maini B (2019b) A review of polymer nanohybrids for oil recovery. Adv Colloid Interface Sci 272:102018
Desplanques S, Renou F, Grisel M, Malhiac C (2012) Impact of chemical composition of xanthan and acacia gums on the emulsification and stability of oil-in-water emulsions. Food Hydrocoll 27(2021):401-410

Eberhard U, Seybold HJ, Floriancic M, Bertsch P, Jimenez-Martinez J, Andrade JS Jr, Holzner M (2019) Determination of the effective viscosity of non-Newtonian fluids flowing through porous media. Front Phys 7:71

Eiroboyi I, Ikiensikimama SS, Oriji BA, Okoye IP (2019) Experimental investigation of the macroscopic displacement efficiency of locally sourced locust bean Gum and Gum Arabic. In: Paper presented at the SPE Nigeria annual international conference and exhibition, Lagos, Nigeria

El-Hoshoudy A, Desouky S, Betiha M, Alsabagh A (2016) Use of 1-vinyl imidazole based surfmers for preparation of polyacrylamide-SiO2 nanocomposite through aza-Michael addition copolymerisation reaction for rock wettability alteration. Fuel 170:161-175

Gashua IB, Williams PA, Yadav MP, Baldwin TC (2015) Characterisation and molecular association of Nigeria and Sundanese Acacia gum exudates. Food Hydrocoll 51(2015):405-413

Hamidi SS, Al-Kayiem HH, Muhsan AS (2020) (2020) Natural polymer non-covalently grafted graphene nanoplatelets for improved oil recovery process: A micromodel evaluation. J Mol Liq 310:113076

Hirasaki GJ, Pope GA (1974) Analysis of factors influencing mobility and adsorption in the flow of polymer solution through porous media. SPE J 14(4):337-346

Ido T, Ogunsawara T, Katayama T, Sasaki Y, Al-Assaf S, Phillips GO (2008) Emulsification properties of GATIFOLIA (Gum Ghatti) used for emulsions in food products. Foods Food Ingred J Jpn 213(4):365-371

Isobe N, Sagawa N, Ono Y, Fujisawa S, Kimura S, Kinoshita K, Miuchi T, Iwata T, Isogai A, Nishino M (2020) (2020) Primary structure of gum arabic and its dynamics at oil/water interfaces. Carbohydr Polym 249:116843

John MF (2017) Experimental study of enhanced oil recovery using silica nanoparticles and gum arabic on medium crude oil and cores of the Nigeria Delta. Masters thesis, Covenant University

Khan M, Khoker F, Husain M, Ahmed M, Anwar S (2018) Effects of nanoparticles on rheological behavior of polyacrylamide related to enhance oil recovery. Acad J Polym Sci 1(5):83-93

Kortam M, Mousa D, Abdeldayim I, Santo G, Lamberti A (2017) Designing and implementing adequate monitoring plan for pilot project of polymer flooding in Belayim Land. In: The 13th offshore mediterranean conference and exhibition, pp 1-25

Lambert-Aikhionbare DO, Shaw HF (1982) Significance of clays in the petroleum geology of the Niger Delta. Clay Miner 17(1):91-103

Li X, Fang Y, Al-Assaf S, Phillips GO, Nishinari K, Zhang H (2009) Rheological study of gum arabic solutions: interpretation based on molecular self-association. Food Hydrocoll 23(8):2394-2402

Li X, Fang Y, Zhang H, Nishinari K, Al-Assaf S, Phillips GO (2011) Rheological properties of gum Arabic solution from Newtonian to thixotropy. Food Hydrocoll 25(3):293-298

Li Y, Dai C, Zhou H, Wang X, Lv W, Zhao M (2017) Investigation of spontaneous imbibition by using a surfactant-free active silica water-based nanofluid for enhanced oil recovery. Energy Fuels 32:287-293

Mariod AA (2018) Functional properties of gum Arabic. In: Mariod AA (ed) Gum Arabic: structures, properties, applications and economics. Academic Press, pp 283-295

Mishra P, Mukherjee S, Nayak S, Panda A (2014) A brief review on viscosity of nanofluids. Int Nano Lett 4:109-120

Negin C, Ali S, Xie Q (2016) Application of nanotechnology for enhancing oil recovery-a review. Petroleum 2:324-333

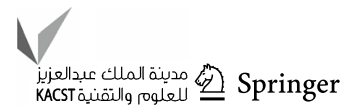


Nowrouzi I, Manshad AK, Mohammadi AH (2019) Effects of ions and dissolved carbon dioxide in brine on wettability alteration, contact angle and oil production in smart water and carbonated smart water injection processes in carbonate oil reservoirs. Fuel 235:1039-1051

Odigi MI (1994) Clay-mineral studies of the subsurface Niger Delta. J Pet Geol 17(4):445-460

Orodu KB, Afolabi RO, Oluwasijuwomi TD, Orodu OD (2019) (2019) Effect of aluminium oxide nanoparticles on the rheology and stability of a biopolymer for enhanced oil recovery. J Mol Liq 288:110864

Patel S, Goyal A (2015) Applications of natural polymer Gum Arabic: a review. Int J Food Prop 18(5):986-998

Rashid F (2019) experimental investigation of the effect of nanoparticle and polymer on interfacial tension between oil and water during enhanced oil recovery (EOR). MSc thesis, University of Salford, Manchester

Rezvani H, Riazi M, Tabaei M, Kazemzadeh Y, Sharifi M (2018) Experimental investigation of interfacial properties in the EOR mechanisms by the novel synthesised Fe3O4@ chitosan nanocomposites. Colloids Surf A Physicochem Eng Asp 544(2018):15-27

Roque ACA, Wilson OC Jr (2007) Adsorption of gum arabic on bioceramic nanoparticles. Mater Sci Eng 28(2008):443-447

Saha R, Uppaluri RV, Tiwari P (2018) Silica nanoparticle assisted polymer flooding of heavy crude oil: emulsification, rheology, and wettability alteration characteristics. Ind Eng Chem Res 57:6364-6376

Sanchez C, Renard D, Robert P, Schmitt C, Lefebvre J (2002) Structure and rheology properties of acacia gum dispersions. Food Hydrocoll 16(2002):257-267

Seright RS, Wang D, Lerner N, Nguyen A, Sabid J, Tochor R (2018) Can 25-cp polymer solution efficiently displace 1,600-cp oil during polymer flooding? SPE J 23(6):2260-2278

ShamsiJezeyi H, Miller CA, Wong MS, Tour JM, Verduzco R (2014) Polymer-coated nanoparticles for enhanced oil recovery. J Appl Polym Sci 131(15):40576(1-13)

Sheng JJ (2011) polymer flooding modern chemical enhanced oil recovery: theory and practice. Elsevier, Oxford, pp 101-206
Sorbie KS (1991) Polymer-improved oil recovery. Springer

Sowunmi A, Orodu OD, Efeovbokhan V, Ogundare S (2020) (2020) Comparative dataset on the characterisation of natural polymers and nanocomposites for enhanced oil recovery. Data $\mathrm{Br}$ 33:106506

Wang D, Cheng J, Xia H, Li Q, Shi J (2001) Viscous-elastic fluids can mobilise oil remaining after water-flood by force parallel to the oil-water interface. In: Paper 72123 presented at the SPE Asia Pacific improved oil recovery conference, Kuala Lumpur, 8-9 October (2001)

Wang D, Cheng J, Yang Q, Gong W, Li Q, Chen F (2000) Viscouselastic polymer can increase microscale displacement efficiency in cores. In: Paper SPE 63227 presented at the SPE annual technical conference and exhibition, Dallas, 1-4 October (2000)

Xiang S, Yao X, Zhang W, Zhang K, Fang Y, Nishinari K, Phillips GO, Jiang F (2015) Gum Arabic_-stabilised conjugated linoleic acid emulsions: emulsion properties in relation to interfacial adsorption behaviours. Food Hydrocoll 48(2015):110-116

Yao X, Xu K, Shu M, Liu N, Na L, Chen X, Nishinari K, Phillips GO, Jiang F (2021) Fabrication of iron loaded whey protein isolate/ gum arabic nanoparticles and its adsorption activity on oil-water interface. Food Hydrocoll 2021:106610 (In Press)

Yu H, Kotsmar C, Yoon KY, Ingram DR, Johnston KP, Bryant SL, Huh C (2010) Transport and retention of aqueous dispersions of paramagnetic nanoparticles in reservoir rocks. In: SPE-129887MS, paper presented at the SPE improved oil recovery symposium, April 24-28 (2010)

Zamani N, Bondino I, Kaufmann R, Skauge A (2017) Computation of polymer in-situ rheology using direct numerical simulation. J Pet Sci Eng 159(2017):92-102

Zhang H, Nikolov A, Wasan D (2014) Enhanced oil recovery (EOR) using nanoparticle dispersions: underlying mechanism and imbibition experiments. Energy Fuels 28:3002-3009

Zou H, Wu S, Shen J (2008) Polymer/silica nanocomposites: preparation, characterisation, properties, and application. Chem Rev 108:3893-3957 